\title{
LA COLOCACION DEL SUJETO Y SU RELACION CON LAS CATEGORIAS DE PRIMERO Y SEGUNDO PLANO EN CASTELLANO
}

Gilda Rosa Arguedas Cortés

\begin{abstract}
The purpose of this article is to analyse the placement of the subject, and the related phenomenon of its omission, in three traditional Central American narratives.

It is shown that, in these texts, the main conditioning factors are the foregrounding and backgrounding strategies characteristic of narrative discourse.
\end{abstract}

\section{INTRODUCCION}

La obra "El orden de palabras en español" (1977) de Heles Contreras parece ser el tratamiento más detallado que ha recibido el tema enunciado en su título. Las conclusiones alcanzadas en ella son de gran interés, pero -como podía esperarse debido a lo complejo del tema- no logran abarcarlo en su totalidad y cabe pensar en superarlas en sus aspectos más discutibles y en complementarlas en aquellos en que ha tenido mayores aciertos.

Una de las afirmaciones más sorprendentes de Contreras (página 22) es que

"la colocación de la cima melódica y el orden lineal de la mayoría de los elementos oracionales no son fenómenos estilísticos".

Esta opinión, tan contraria a la que tradicionalmente se ha tenido, se debe a los factores que se comentan a continuación.

Contreras concibe lo estilístico como (ibídem) "la variación que resulta de las distintas opciones libremente escogidas por el hablante". Como encuentra que hay puntos en el discurso en los que no se puede cambiar libremente el orden, concluye que este fenómeno no es estilístico. Este razonamiento, sin embargo, no parece válido, pues el hecho de que haya puntos en el discurso en que el orden no es "libremente" intercambiable, no ex- cluye que haya otros puntos en que sí lo es. Este hecho se puede comprobar con facilidad en numerosos textos. Para dar un ejemplo, en uno de los textos usados en este trabajo (Constenla, 1985, p. 51) se encuentra la siguiente oración que admite (en su contexto) el cambio de posición de sujeto sin que para ninguna persona consultada se afecte perceptiblemente ni el valor semántico ni el sintáctico de la oración.

"Entonces eeeh, Tío Conejo comenzó a hacer esa cantidad de muñecos de cera, veá".

"Entonces eeeh, comenzó Tío Conejo a hacer esa cantidad de muñecos de cera, veá".

"Entonces eeeh, comenzó a hacer Tío Conejo esa cantidad de muñecos de cera, veá".

Por supuesto, la forma de ver Contreras el problema sólo es válida en una obra escrita totalmente al margen de los estudios que desde los sesentas se vienen realizando sobre la variación en el lenguaje. Estos estudios (véase, por ejemplo, Sankoff, 1974) han demostrado que la variación libre, en sentido estricto, no es un hecho tan frecuente en la lengua como se había pensado y que una buena parte de los casos en que los estudios no variacionistas pretenden que se da, los fenómenos presentan diversos condicionamientos, unas veces lingüísticos, otras extralingüísticos y a veces de ambos tipos, que determinan la mayor o menor frecuencia de las formas en alternancia. En vista de esta realidad, la exigencia de Contreras de una va- 
riación totalmente libre excluiría la posibilidad de que lo estilístico exista.

Aunque Contreras menciona el discurso y recurre a categorías propias de su análisis, como "información nueva" e "información vieja", su marco teórico es obviamente el de una gramática cuya unidad mayor es la oración. Sus ejemplos son oraciones aisladas, creadas por él o tomadas de obras literarias, a las que a lo sumo se les ha dado como entorno una pregunta, otra oración del mismo tipo con que pueden coordinarse o no, o un pretendido punto del discurso tal como "el comienzo". No es de extrañar que dentro de tales límites, las principales reglas de ordenamiento tengan para él carácter categórico: la variación se descubre en otro tipo de corpus, particularmente en este caso, en textos. Llama la atención que, habiendo planteado la oposición entre "tema" (información vieja) y "rema" (información nueva) como el principal factor condicionante del orden de las palabras, afirme la ausencia de variación estilística en este fenómeno. Como ha señalado Chafe (1976, p. 32):

\footnotetext{
“El tratamiento de un elemento como información vieja por parte del hablante... debiera cesar cuando éste juzgue que el elemento ha abandonado la conciencia de la persona a la que se dirige. Este tipo de juicio puede resultar difícil de hacer y esta es una área en que los hablantes tienen especial propensión a equivocarse".
}

De todos modos, en un estudio limitado al nivel oracional, los términos como "tema" y "rema" resultan un tanto vacíos. Por ejemplo, Contreras nos habla de una selección remática típica y otra atípi$\mathrm{ca}$, sin embargo no nos aclara cuándo se da la una o la otra ni por qué se prefiere una de ellas en determinados casos. Este hecho no es una particularidad de dichas categorías, lo mismo sucede, por ejemplo, con los aspectos verbales: su explicación última está en el uso que se les da en los textos (que puede, incluso, variar mucho según el tipo de texto).

Finalmente, cabe señalar que muchas de las aseveraciones de Contreras, como suele ocurrir en las gramáticas basadas más que nada en la intuición personal, parecen gratuitas, como -por ejemplo- el considerar agramatical la siguiente oración (p. 47):

Lamento que la resistencia empezara

o sostener que

Fracasó la resistencia

sólo puede ser respuesta de ¿Qué fracasó? y no de ¿Qué pasó?
Encontrar contraejemplos a muchas de sus afirmaciones en textos concretos no es tampoco tarea difícil. Por ejemplo, afirma que oraciones como (p. 61)

Los camiones los mandan ellos

Eso lo arreglaré yo mismo

Lo llama el director

sólo pueden ser respuestas a preguntas iniciadas por quién y no a la pregunta iqué pasa? No obstante, en uno de los textos utilizados en este trabajo, se dan cuatro veces secuencias como la siguiente:

- ¿Qué quieres, amo -le dice, le dice- de la selva? -le dice-iqué quieres?

Le dijo al hombre, vedá, porque el tigre respetaba al hombre.

$Y$ dice:

-Vieras - dice -, estoy en un apuro, que no hallo qué hacer, le dice. Eeeh... mi esposa-dice-me la robó un gigante...

En vista de todo lo anterior, mi opinión es que sólo un análisis sociolingü ístico cuantitativo basado en categorías propias del análisis del discurso podría producir resultados totalmente convincentes en materia del orden de las palabras en castellano.

Mi intención en este trabajo no es producir dicho tipo de estudio -que exigiría una muestra más representativa que la empleada aquí -sino aportar indicios a favor de la idea de que el orden del verbo y su sujeto en castellano está relacionado con las categorías de primer plano y segundo plano del discurso narrativo, pero que esta relación no es categórica sino un asunto de distinto grado de probabilidad. Con este fin, he analizado tres cuentos folclóricos: "Tío Conejo sacó al hombre de apuros", narrado por un campesino de Juan Viñas Mario Loaiza - a Adolfo Constenla (1985). "Los dos compadres", de la colección Cuentos viejos de María de Noguera, y "Tío Coyote y Tío Conejo" recogido por Pablo Antonio Cuadra en Granada (Nicaragua) y publicado como libro por EDUCA.

\section{LOS CONCEPTOS DE "PRIMER PLANO" $Y$ "SEGUNDO PLANO DEL DISCURSO NARRATIVO" Y LA COLOCACION DEL SUJETO}

Hopper (1979) ha propuesto la existencia de la oposición entre primer plano (foregrounding) y segundo plano (backgrounding) como un universal del discurso narrativo. 
De acuerdo con él, el primer plano comprende la línea o estructura básica de la narración y el segundo plano el material de refuerzo que por sí mismo no se usa para narrar los sucesos principales. Los hechos pertenecientes al primer plano tienen necesariamente un orden de secuencia entre sí; los del segundo plano, en cambio, no presentan esta característica. El no tener "secuencialidad" como requisito hace que las cláusulas del segundo plano se puedan localizar en cualquier punto del eje temporal y no tengan mayor cohesión.

Lo anterior incide en que la estructura remática de las cláusulas de uno y otro plano sea muy diferente. En las cláusulas de segundo plano hay mayor tendencia a cambiar de tema y a presentar información nueva en la posición preverbal, en tanto en las cláusulas de primer plano los sujetos son muy presuposicionales y el material nuevo se presenta en el predicado.

Antes de pasar a tratar hasta qué punto se cumplen las ideas de Hopper que he resumido en los párrafos anteriores en los textos analizados, he de señalar que las partes de los mismos ocupadas por diálogo no se han tomado en cuenta ni como primer plano ni como segundo pues se consideran como un tercer componente aparte. Hopper no hace referencia al diálogo (que -sin embargo- se da con tanta frecuencia en algunos tipos de narraciones), pero mi impresión es que su "segundo plano" coincide, en términos generales, con el componente de "orientación" de Labov (1972) y no con el de "evaluación" al que parecen pertenecer esencialmente los diálogos en los textos analizados.

Por otra parte, no se han tomado en cuenta tampoco, los sujetos constituidos por pronombres relativos, ya que no pueden colocarse sino a la izquierda del verbo.

Para distinguir las cláusulas de primer plano de las de segundo plano, el principal criterio empleado fue el de la secuencialidad. Además, se tomaron en cuenta factores como la presencia del pretérito indefinido de indicativo y del presente histórico que se relacionan con el primer plano y la del pretérito imperfecto, las formas del modo potencial y del subjuntivo y las formas negativas que se relacionan con el segundo plano según diversos estudios (Labov, 1972; Weinrich, 1973; Hopper, 1979).

Hechas estas salvedades, los siguientes cuadros muestran el resultado del conteo de sujetos presentes en los trozos de las narraciones analizadas pertenecientes al primero $y$ al segundo planos:
Cuento "Tío Conejo sacó al hombre de apuros", Mairo Loaiza (Juan Viñas, Cartago)

Sujetos Presentes

Antepuestos Pospuestos Totales

$\begin{array}{lccc}\begin{array}{l}\text { Cláusulas de } \\ \text { primer plano }\end{array} & \begin{array}{c}23 \\ (36.5 \%)\end{array} & \begin{array}{c}40 \\ (63.5 \%)\end{array} & 63 \\ \begin{array}{l}\text { Cláusulas de } \\ \text { segundo plano }\end{array} & 21 & 10 & 31 \\ & (67,7 \%) & (32.3 \%) & \end{array}$

Cuento "Los dos compadres" de la colección Cuentos Viejos de María de Noguera

Sujetos Presentes

Antepuestos Pospuestos Totales

$\begin{array}{lccc}\text { Cláusulas de } & 19 & 34 & 53 \\ \text { primer plano } & (36 \%) & (64 \%) & \end{array}$

Cláusulas de

segundo plano

$(71 \%)$

9

$(29 \%)$

31

Cuento "Tío Coyote y Tío Conejo" recogido por Pablo Antonio Cuadra (Granada, Nicaragua).

Sujetos Presentes

Antepuestos Pospuestos Totales

$\begin{array}{lccc}\begin{array}{l}\text { Cláusulas de } \\ \text { primer plano }\end{array} & 18 & 23 & 41 \\ & (44 \%,) & (56 \%) & \\ \begin{array}{l}\text { Cláusulas de } \\ \text { segundo plano }\end{array} & 19 & 7 & 26\end{array}$

Como se puede ver, uno y otro tipo de cláusula muestran frecuencias inversas de los dos tipos de colocación del sujeto, $y$, lo que es más interesante, en las cláusulas en que, de acuerdo con Hopper el sujeto suele ser tema y el predicado rema, el orden más frecuente es predicado-sujeto (y viceversa). De ser cierto que el rema tiende a colocarse después del tema, esto querría decir que la narración folclórica del tipo analizado aquí, va en buena parte contra esta tendencia (es decir, que en ella tendría un papel muy importante lo que Contreras denomina "orden enfático").

En relación con las cifras anteriores, es interesante que en inglés antiguo -la lengua usada por Hopper para ejemplificar el uso del orden de las 
palabras para manifestar las categorías de primer plano y segundo plano -el orden SV correspondiera al segundo plano y el orden VS al primero (Hopper, ibídem, pp. 220-226).

\section{RELACION ENTRE LA COLOCACION DEL SUJETO Y SU OMISION}

Otro aspecto interesante de los sujetos en castellano que se encuentra sometido a variación es la presencia o ausencia del sujeto.

La observación de este fenómeno en los textos analizados muestra que se relaciona, al igual que la colocación del sujeto, con los dos planos de la narración. Esto se comprueba en las siguientes tablas, en las que se ha hecho el conteo de los verbos conjugados que pueden tanto llevar sujeto como no llevarlo incluidos en las porciones de las narraciones consideradas como parte de uno u otro plano. En el caso del cuento "Tío Conejo sacó al hombre de apuros", no se tomaron en cuanta las apariciones del verbo decir, que se da 236 veces sin sujeto y 14 con sujeto pospuesto integrado por frases nominales.

Cuento "Tío Conejo sacó al hombre de apuros"

\section{Cláusulas de primer plano}

$\begin{array}{lc}\text { Verbos sin sujeto } & 111 \\ (69 \%)\end{array}$

Verbos con sujeto

Totales

160

Cuento "Los dos compadres"

\section{Cláusulas de} primer plano

Verbos sin sujeto

69

Verbos con sujeto

Totales
Cláusulas de segundo plano

Cláusulas de segundo plano
Cuento "Tío Coyote y Tío Conejo"

$\begin{array}{ll}\text { Cláusulas de } & \text { Cláusulas de } \\ \text { primer plano } & \text { segundo plano }\end{array}$

Verbos sin sujeto

\section{7}

$(58 \%)$

Verbos con sujeto

41

$(42 \%)$

98

Totales
En mi opinión, el mayor grado de omisión del sujeto en las cláusulas de primer plano se explica por dos características de las mismas: el carácter presuposicional de sus sujetos y su tendencia a la posición posverbal.

Si se considera que los sujetos omitidos son los pronombres personales (como generalmente se hace, véase p.e. Cifuentes, 1980-1), se ve claramente el por qué de la mayor tendencia a la omisión: si los pronombres sujetos en sí no añaden mucha información a la incluida en las desinencias del verbo, su presencia será mucho menos útil colocados después de dichas desinencias que antes de ellas.

\section{CONCLUSION}

Creo haber aportado buenos indicios de la existencia de una relación entre los planos de la narración y la colocación del sujeto. De seguro que los planos de la narración no son el único factor que influye en la colocación del sujeto, básicamente porque no todos los textos son narrativos, pero también porque hay otros factores que intervienen (el verbo es sin duda uno de ellos, decir -por ejemplo- favorece clarísimamente la posposición).

Pienso que la posición del sujeto es variable en la mayor parte de los casos y que existen diversos factores que favorecen una u otra colocación en relación con el verbo. Estos factores colaboran entre sí de modo que el grado de probabilidad de que el sujeto de un verbo se posponga será mucho mayor si el verbo es decir y al mismo tiempo pertenece al primer plano, que si se da uno solo de dichos factores. Todo esto, sin embargo, sólo se podrá determinar bien -como lo señalé antes- en un estudio cuantitativo. 


\section{BIBLIOGRAFIA}

Cifuentes, H. "Presencia y ausencia del pronombre personal sujeto en el habla culta de Santiago de Chile", Boletín de Filología (Universidad de Chile) 31 (2): 743-752. 1980-1981.

Contreras, H. El orden de palabras en español. Madrid: Ediciones Cátedra, S.A. 1978.

Constenla Umaña, A. "Funciones del presente histórico en dos textos narrativos tradicionales costarricenses". Revista de Filología 1985.

Chafe, W. "Givenness, contrastiveness, definiteness, subjects, topics and point of view". En: Subject and Topic compilado por Charles Li. Nueva York: Academic Press. 1976.
Hopper, P.J. "Aspect and foregrounding in Discourse". En: Syntax and Semantics 12, Discourse and Syntax, compilado por Talmy Givón. Nueva York: Academic Press. 1979.

Labov, W. "The Transformation of Experience in Narrative Syntax". En: Language in the Inner City: Studies in the Black English Vernacular. Filadelfia:University of Pennsylvania Press.1972.

Sankoff, G. "A quantitative paradigm for the study of communicative competence". En: Exp/orations in the Ethnography of Speaking, compilado por R. Bauman y J. Sherzer. Londres: Cambridge University Press. 1974.

Weinrich, H. Le temps. París: Editions du Seuil. 1973 
. 